\title{
Domino Synthesis of Benzo-fused $\beta, \gamma$-Unsaturated Ketones from Alkenylboronic acids and N-Tosylhydrazone-tethered Benzonitriles
}

\author{
M anuel Plaza, M iguel Paraja, Lucía Florentino and Carlos Valdés*
}

Departamento de Química Orgánica e Inorgánica and Instituto Universitario de Química Organometálica "Enrique Moles". U niversidad de 0 viedo. cl Julián Clavería 8. O viedo 33006. Spain.

Supporting Information Placeholder

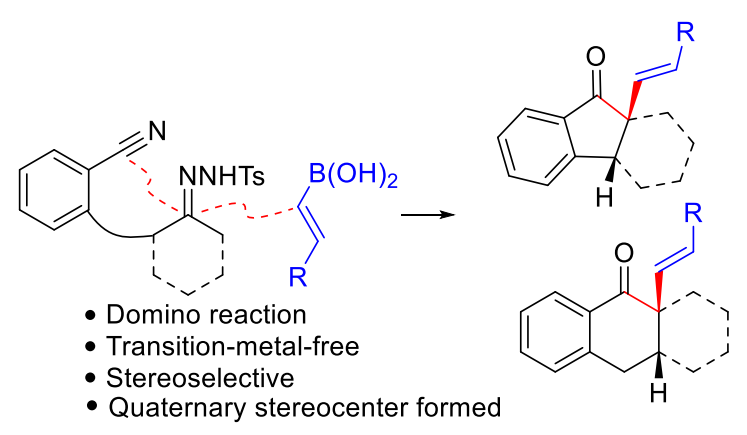

\begin{abstract}
ABST RACT: T hetransition metal-free domino reaction between alkenylboronic acids and N-tosylhydrazones from 0-( 2-oxoalkyl)- and 0-(3oxoalkyl) benzonitriles leads to $\beta, \gamma$-unsaturated indanones and tetralones featuring an $\alpha$-"all-carbon" quaternary center. The employment of derivatives of $\alpha$-substituted cyclopentanones and cyclohexanones led to the stereoselective preparation of $\beta, \gamma$-unsaturated tetrahydrocyclopenta[a]inden-8( $1 \mathrm{H})$-ones, hexahydrofluorenones and hexahydroanthracenones as cis-fused single stereoisomers. A domino sequence involving diazo compound formation/ reductive alkenylation/ 1,3-borotropic rearrangement/ intramolecular bora-aza-ene reaction is proposed to justify the formation of the products as well as the stereoselectivity.
\end{abstract}

Cyclic scaffolds featuring "all-carbon" quaternary sterocenters are structural motifs found in many biologically active natural and unnatural molecules. ${ }^{1}$ Among the synthetic methods to achieve the construction of these challenging structures, carbocyclization processes that take place with formation of two $\mathrm{CSp}^{3}-\mathrm{C}$ bonds on the same carbon atom are very efficient yet unconventional solutions, that in most of the cases, take place through transition metal catalyzed cascade reactions. ${ }^{2,3}$ In particular, processes that generate a bridgehead "all-carbon" quaternary center ${ }^{4}$ during the cyclization are particularly appealing. These transformations enable the synthesis of molecular scaffolds with well defined three-dimensional arrangements in a straightforward manner. In the recent years, we have concentrated in these synthetic strategies both through Pd-catalyzed ${ }^{5}$ and transition-metal-free reactions, ${ }^{6}$ employing $\mathrm{N}$-tosylhydrazones as the divalent $\mathrm{C} 1$-synthon that can participate in the formation of the two bonds through cascade reactions. ${ }^{7}$ In particular, we have recently uncovered a cascade carbocyclization between $\gamma$ - and $\delta$-cyano-N -tosylhydrazones and alkenyl boronic acids, which provides substituted cyclopentanones and cyclohexanones featuring an "allcarbon" quaternary center. ${ }^{6 a}$ In these processes, carbocyclization and incorporation of a side chain occur during the domino reaction. We have also shown that this strategy can be applied for the construction of a variety of complex polycyclic carbo- and heterocycles as well as spirocycles featuring a bridgehead quaternary center. ${ }^{6 b} \mathrm{Ac}$ cording to our computational studies, the cascade reaction may involve formation of an allylboronic acid by carboborylation of the $\mathrm{N}$ tosylhydrazone, followed by intramolecular allylborylation of the nitrile through an intramolecular bora-aza-ene reaction (Scheme 1, a). To expand the usefulness of this transformation, we decided to investigate if the domino reaction could be applied also to benzonitrile tethered $\mathrm{N}$-tosylhydrazones. This reaction might enable the preparation of benzofused $\beta, \gamma$-unsaturated ketones, ${ }^{8}$ such as vinylindanones and tetralones, featuring an "all-carbon" quaternary center (Scheme 1, b). These classes of carbocyclic scaffolds might be very relevant for their usefulness as synthetic precursors, ${ }^{9}$ and also due to their interest in drug discovery. ${ }^{10}$

We started our investigation considering the $\mathrm{N}$-tosylhydrazone $1 \mathrm{a}$ derived from 2-(2-oxopropyl) benzonitrile and 3-phenylprop-1-en1 -yl) boronic acid $2 a$, that might lead to the $\beta$ - $\gamma$-unsaturated indanone $3 a$ (Scheme2). After some experimentation, we found that the reaction conditions that we had originally developed for the reactions involving alkyl nitriles were also appropriate for the reaction with the benzonitrile. 
Scheme 1. (a) D omino reaction between $\gamma$-cyano-N-tosylhydrazones and alkenylboronic acids for the synthesis of $\beta$ - $\gamma$-unsaturated ketones. (2) This work.

a) Our previous work

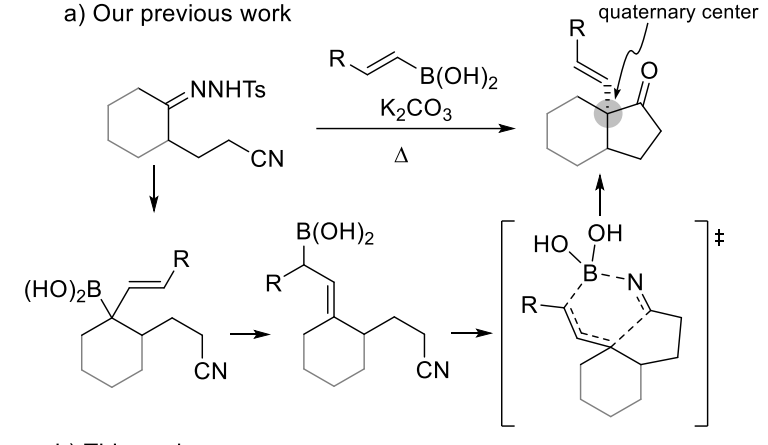

b) This work<smiles>[R]C=C[Hg]O</smiles><smiles>[R]C=CC1CCCCC1C(=O)c1ccccc1N</smiles>

Thus, by treating the $\mathrm{N}$-tosylhydrazone 1 a with alkenylboronic acid $2 \mathrm{a}$, in the presence of $\mathrm{K}_{2} \mathrm{CO}_{3}$ as base, in 1,4-dioxane as solvent, under microwave irradiation at $120^{\circ} \mathrm{C}$ for $4 \mathrm{~h}$, the 2,2,-disubstituted indanone $3 a$ was obtained with good yield through the desired domino alkenylation/ carbocyclization (Scheme2). The reaction exhibited a wide scope with regard to substitution in the alkenylboronic acids $\mathbf{2}$, including the presence of a M O M group ( $\mathbf{3 b}$ ), and the potentially reactive alkylchloride functionality in the side chain ( $\mathbf{3 e}$ ) that may enable further diversification. Interestingly, the use of phenylvinylboronic acid, which did not perform well in our previous studies, also granted the formation of the indanone $\mathbf{3 g}$. Finally, the reaction was also applied to the $\mathrm{N}$-tosylhydrazone of 4-butenyl phenyl ketone $\mathbf{~} \mathbf{c}$, leading to 2-vinyl-2-allylindanones 3i-k (Scheme 2).

We next turned our attention to the synthesis of 2,2-disubstituted tetralones through the same methodology. To this purpose the $\mathrm{N}$ tosylhydrazone $\mathbf{4}$ featuring an additional methylene group in the tether between the hydrazone and the cyano functionalities was employed. Pleasantly, under similar reaction conditions, the expected $\beta, \gamma$-unsaturated tetralones $\mathbf{5}$ were obtained with fairly good yields and similar scope regarding the alkenylboronic acid (Scheme 2).

$N$ oteworthy, this is indeed an original procedure for the construction of the indanone and tetralone scaffolds that implies cyclization and incorporation of a side chain in the domino process. It must be noted that typical methods for the synthesis of substituted indanones and tetralones are carried out by introducing a substituent to the existing cyclic ketone, ${ }^{8,11}$ or by cyclization of an acyclic system that already incorporates all the substitutions. ${ }^{12}$ In contrast, our methodology integrates both steps in the domino process, allowing for an easy diversification, and remarkably, in a very simple process that does not even require the employment of transition metal catalysts.

In order to apply this methodology to more challenging and synthetically attractive substrates, we turned our attention to $\mathrm{N}$-tosylhydrazones 6 and 7, readily available from 2-(0-cyanophenyl) cyclopentanone and 2-(0-cyanophenyl)cyclohexanone respectively (Scheme 3).

Scheme 2. Synthesis of 2,2-disubstituted $\beta, \gamma$-unsaturated indanones 3 and tetralones 5 by reaction of $\mathbf{N}$-tosylhydrazones 1 and 4 with alkenylboronic acids 2 , $^{\mathrm{a}, \mathrm{b}}$

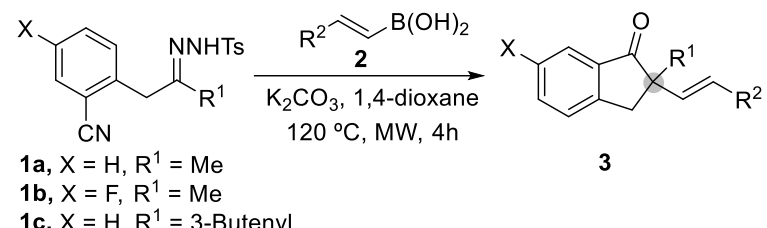

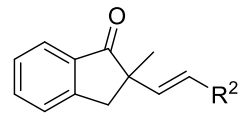

3a, $\mathrm{R}^{2}=\mathrm{Bn}$

$-\mathrm{CH}_{2} \mathrm{OCH}_{3}(62 \%)$

3c, $\mathrm{R}^{2}=n$-Propyl $\quad(78 \%)$

3d, $\mathrm{R}^{2}=n$-Hexyl $\quad(68 \%)$

3e, $\mathrm{R}^{2}=-\left(\mathrm{CH}_{2}\right)_{3}-\mathrm{Cl} \quad(84 \%)$

3f, $\mathrm{R}^{2}=$ Cyclohexyl $(71 \%)$

$3 \mathrm{~g}, \mathrm{R}^{2}=\mathrm{Ph}$

$(43 \%)$

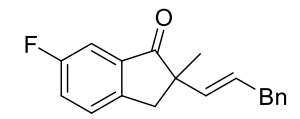

3h, $(57 \%)$

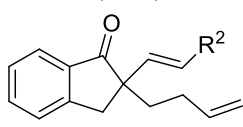

$3 \mathbf{i}, \mathrm{R}^{2}=\mathrm{Bn} \quad(62 \%)$

3j, $\mathrm{R}^{2}=-\left(\mathrm{CH}_{2}\right)_{3}-\mathrm{Cl}(65 \%)$

3k, $\mathrm{R}^{2}=n$-Propyl $\quad(73 \%)$

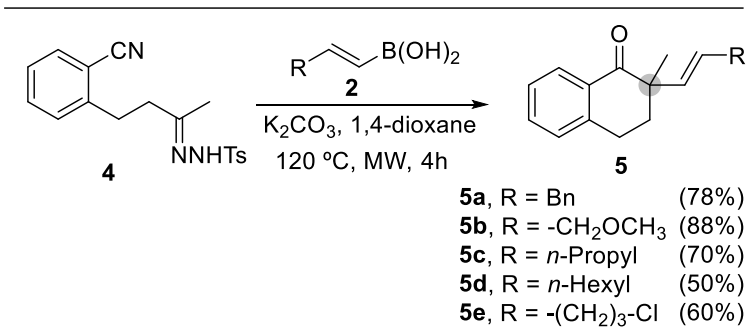

aReaction conditions: $\mathrm{N}$-tosylhydrazone $\mathbf{1}$ or $\mathbf{4}(0.15 \mathrm{mmol})$, boronic acid 2 ( $0.3 \mathrm{mmol}$ ), $\mathrm{K}_{2} \mathrm{CO}_{3}$ ( 2 equiv), 1,4-dioxane ( $1.2 \mathrm{~mL}$ ), microwave irradiation, $120 \stackrel{\circ}{ } \mathrm{C}$, $4 \mathrm{~h}$. ${ }^{\mathrm{b}}$ Y ields represent isolated yields after column chromatography.

These reactions were particularly interesting for various reasons: i) the presence of a stereogenic center at the $\alpha$-position of the $\mathrm{N}$-tosylhydrazone might allow to study the diastereoselectivity of the reaction; ii) the expected reaction products feature scaffolds, such as hexahydrofluorenone, that are present in a large number of natural products and biologically active molecules. ${ }^{13}$

D elightfully, under the standard conditions the final products were furnished as pure diastereoisomers to afford substituted tetrahydrocyclopenta[a]inden-8(1H)-ones 8 and hexahydrofluorenones $\mathbf{9}$ from $\mathbf{N}$-tosylhydrazones $\mathbf{6}$ and $\mathbf{7}$ respectively (Scheme 3). As determined by $2 \mathrm{D}-\mathrm{N} M \mathrm{R}$ and selective $\mathrm{nO}$ e experiments, the diastereoisomers featuring a cis fusion between the rings were always obtained. ${ }^{14} \mathrm{~N}$ oticiable, this stereoselectivity could be reproduced regardless of the size ( five- or six-membered ring) of the preexisting ring.

Finally, the cascade reaction was also studied with $\mathrm{N}$-tosylhydrazones 10 , that would hopefully provide $\beta, \gamma$-unsaturated hexahydroanthracenones upon cyclization with formation of a six-membered ring (scheme 4). M uch to our surprise, upon reaction with alkenyl boronic acids $\mathbf{2}$ under the standard conditions, instead of the expected hexahydroanthracenones $\mathbf{1 2}$, the corresponding $\mathrm{NH}$ ketimines $\mathbf{1 1}$ were obtained with excellent yields. Thus, in these cases, the hydrolysis of the imine under the reaction conditions was prevented, probably due to thesteric congestion around the benzylic position. 
Scheme 3. Stereoselective synthesis of tetrahydrocyclopenta[a] inden-8(1H) -ones 8 and hexahydrofluorenones $9 .^{a, b}$

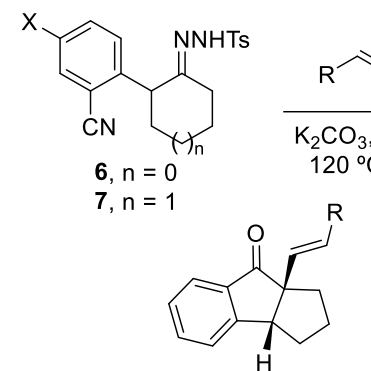

8a, $\mathrm{R}=\mathrm{Bn}$

8 b, $\mathrm{R}=-\left(\mathrm{CH}_{2}\right)_{3}-\mathrm{Cl}(56 \%)$

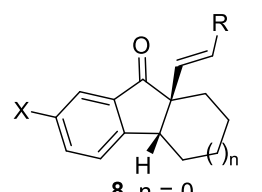

$8, n=0$ Bn $9, n=1$

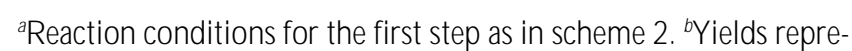
sent isolated yields after column chromatography.

This is indeed an interesting result, since it is the first time that the $\mathrm{N} \mathrm{H}$-ketimine is isolated in these intramolecular carborylation reactions. $N$ evertheless, the imine could be efficiently hydrolyzed upon stirring in a silica gel suspension in methylene chloride to give hexahydroanthracenones 12. As an exception, the reaction with $\mathrm{N}$-tosylhydrazone $\mathbf{1 0 b}$, derived from $\mathrm{N}$-benzyl-4-piperidone led directly to the ketone $\mathbf{1 2 e}$, and the imine could not be isolated. Importantly, compounds $\mathbf{1 1}$ and $\mathbf{1 2}$ were isolated as uniquediastereoisomers, and again with a cis-fusion between the saturated rings. ${ }^{14}$

\section{Scheme 4. Sereoselective synthesis of hexahydroanthracenone} derivatives 11 and $12 .{ }^{a, b}$

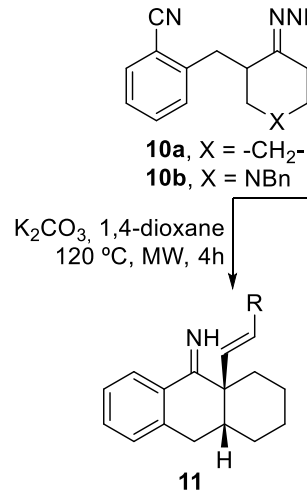

$11 \mathrm{a}, \mathrm{R}=\mathrm{Bn},(97 \%)$

11b, $\mathrm{R}=n-\operatorname{Pr},(74 \%)$

$11 \mathrm{c}, \mathrm{R}=\mathrm{Ph},(77 \%)$

11d, $\mathrm{R}=-\left(\mathrm{CH}_{2}\right)_{3} \mathrm{Cl},(89 \%)$ 12d, $X=\mathrm{CH}_{2}, \mathrm{R}=-\left(\mathrm{CH}_{2}\right)_{3} \mathrm{Cl},(72 \%)$

12e, $\mathrm{X}=\mathrm{N}-\mathrm{Bn}, \mathrm{R}=n-\mathrm{Pr},(55 \%)$

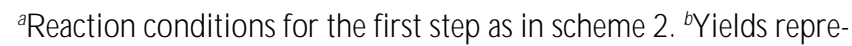
sent isolated yields after column chromatography.

The ketimines 11 might be susceptible to further simple functional group manipulations leading to the corresponding benzylamine derivatives. For instance, benzoylation of $\mathbf{1 1} \mathbf{b}$ led to $\mathrm{N}$-benzoylimine 13 and subsequent treatment with $\mathrm{LiAlH}_{4}$ furnished $\mathrm{N}$-benzamide 14. N oteworthy, the reduction takes place in a stereoselective manner leading to the amide $\mathbf{1 4}$ featuring three contiguous stereogenic centers as a unique diastereoisomer (Scheme 5 ). ${ }^{14}$

Scheme 5. Stereoselective reduction of ketimine $11 \mathrm{~b}$.

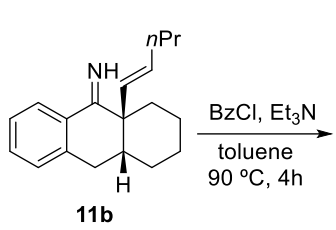

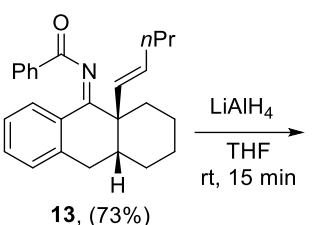<smiles>CC(C)CCC1(CCC(C)(C)C)CCCCC1(NC(=O)c1ccccc1)c1ccccc1</smiles>

$M$ echanistic considerations: Like in our preceeding contributions, the reactions with arylboronic acids did not provide the analogous cyclization products, but instead the typical reductive arylation of the $\mathrm{N}$-tosylhydrazone took place. This observation points again to the necessity of an intermediate allylboronic acid to promote the intramolecular carboborylation of the nitrile. As presented in Scheme 6, a plausible mechanism, in agreement with our DFT computational studies would involve: 1) decomposition of the $\mathrm{N}$-tosylhydrazoneto give the diazo compound $\mathbf{A}{ }^{15}$ 2) carboborylation of the diazo compound to give allyl boronic acid $\mathbf{B}_{1}{ }^{16} 3$ ) borotropic rearrangement to provide allylboronic acid $\left.\mathbf{C}_{1}{ }^{17} 4\right)$ concerted carboborylation of the nitrile through a bora-aza-ene reaction to give $\mathrm{N}$-boroimine $\mathbf{D}$, which upon hydrolysis would furnish the final ketones.

Scheme 6. Mechanism proposed based on DFT computational modeling studies.
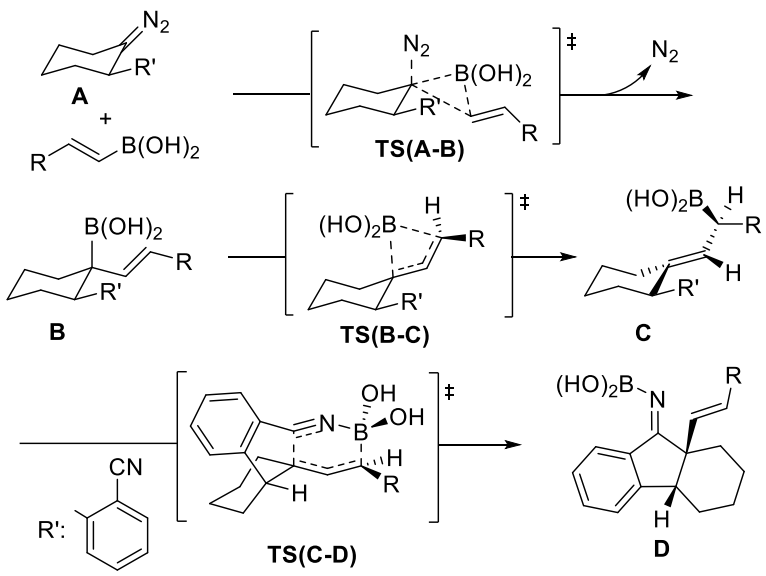

Interestingly, this reaction model can also explain the stereoselectivity observed in the reactions with $\mathrm{N}$-tosylhydrazones 6, 7 and $\mathbf{1 0}$ which lead to the cis-fused condensed ketones $\mathbf{8 , 9}$ and $\mathbf{1 2}$ respectively. Although, the concerted carboborylation reaction could occur to give both the cis-fused and the trans-fused bicyclic ketones, DFT -based molecular modeling computations clearly show that the bora-aza-eneconcerted transition states that giverise to the cis-fused systems are considerably favoured for both the 5-6 and the 6-6 systems. Inspection of the molecular models reveal that the transition states that would give rise to the trans-fused systems are substantially distorted from theideal geometry of the six-centered transition state, while for the cis-fused systems are closer to the ideal geometry of the transition state of the bora-aza-ene reaction (Figure 1). A detailed computational study for both systems is provided in the SI.

In summary, we have developed a new method for the synthesis of $\beta, \gamma$-unsaturated indanones and tetralones featuring an $\alpha$-quaternary center by reaction of alkenylboronic acids with $\mathrm{N}$-tosylhydrazones tethered to a benzonitrile. In the domino reaction the incorporation of the alkenyl group and the cyclization reaction occur in a single step. 


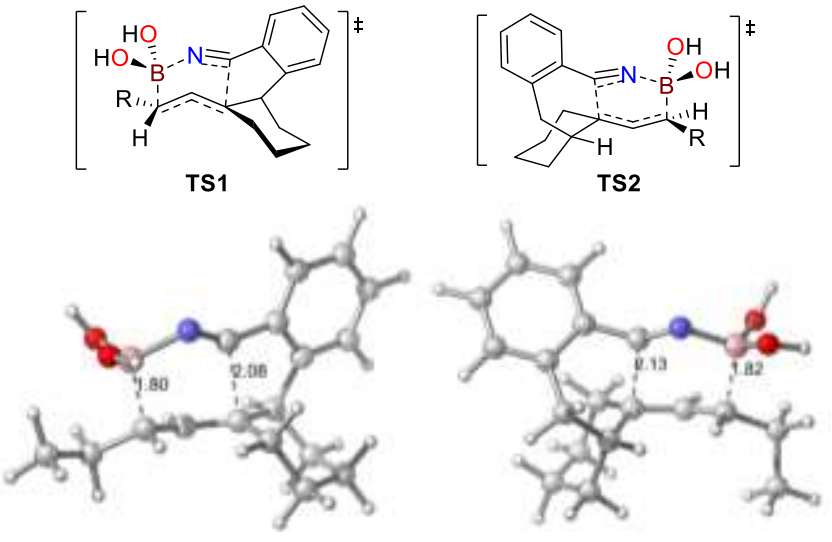

Figure 1: Molecular models for the lowest energy transition states ( $\mathrm{M}$ 06-2X / 6-311++G**) for the concerted carboborylations, that lead to the cis-fused indanones $\mathbf{9}$ (TS1) and anthracenones $\mathbf{1 1}$ (TS2) respectively.

\section{ASSOCIATED CONTENT}

\section{Supporting Information}

The Supporting Information is available free of charge on the ACS Publications website.

Experimental procedures, compound characterization data, and N M R spectrafor the compounds described. Computational molecular modeling studies.

\section{AUTHOR INFORMATION}

\section{Corresponding Author}

*CarlosValdés. E-mail: acvg@ uniovi.es.

ORCID: Carlos Valdés: 0000-0002-6246-2994

\section{ACKNOWLEDGMENT}

Financial support of this work by M inisterio de Economía y Competitividad ( M INEC O) of Spain: Grant CT Q 2016-76794-P (AEI/ FEDER UE) . A FPI predoctoral fellowship ( M INECO) to M . Paraja and aFPU predoctoral fellowship (MECD) to M. Plaza are gratefully acknowledged. Lucía. F. wish to thank Principado de Asturias for a M arie C urie - Clarín cofund postdoctoral fellowship (ref: PA-18-ACB17-20).

\section{REFERENCES}

(1) (a) Christoffers, J.; Baro, A. Eds. Quaternary stereocenters: Challenges and solutions for organic synthesis. Wiley-VCH: Weinheim, 2005. (b) Liu,Y.; H an, S.-J.; Liu, W.-B.; Stoltz, B. M . Acc. Chem. Res. 2015, 48, 740 .

(2) For some selected recent examples of metal catalysed cyclizations with formation of two bonds on the same carbon: ( a) Yada, A.; Fujita, S.; M urakami, M. J. Am. Chem. Soc. 2014, 136, 7217. (b) Xia, Y.; Liu, Z.; Liu, Z.; Ge, R.; Ye, F.; H ossain, M .; Zhang, Y.; Wang, J. J. Am. Chem. Soc. 2014, 136, 3013. (c) Li, S.-S.; Lin, H .; Liu, C.- F.; Xia, Y.-Q .; Zhang, X.-M .; D ong, L. Adv. Synth. Catal. 2016, 358, 1595. (d) Gutiérrez-Bonet, A.; Juliá-H ernández, F.; de Luis, B.; M artín, R. J. Am. Chem. Soc. 2016, 138, 6384. (e) Wang, G.-W.; M cC reanor, N. G.; Shaw, M . H .; Whittingham, W. G .; Bower, J. F. J. Am. Chem. Soc. 2016, 138, 13501. (f) Xu, S.; Chen, R.; Fu, Z.; Zhou, Q .; Zhang, Y.; W ang, J. ACS Catalysis 2017, 7, 1993.
(3) Selected examples of metal catalyzed spirocyclizations with formation of two bonds on the same carbon: (a) Bai, L.; Yuan, Y.; Liu, J.; Wu, J.; H an, L.; Wang, H .; Wang, Y.; L uan, X. Angew. Chem. Int. Ed. 2016, 55, 6946. c) Liu, Y.; Song, R.-J.; Li, J.-H. Chem. Commun. 2017, 53, 8600. (d) Zuo, Z.; Wang, H.; Fan, L.; Liu, J.; Wang, Y.; Luan, X. Angew. Chem. Int. Ed. 2017, 56, 2767. (e) Pérez-Gómez, M.; H ernández-Ponte, S.; Bautista, D.; García-López, J.-A. Chem. Commun. 2017, 53, 2842.

(4) (a) Quasdorf, K. W. O verman L. E. N ature 2014, 516, 181. (b) Ling, T .; Rivas, F. T etrahedron 2016, 72, 6729.

(5) (a) Barroso, R.; Valencia, R. A.; Cabal, M .-P.; Valdés, C. O rg. Lett. 2014, 16, 2264. (b) Barroso, R.; C abal, M .-P.; Badia-Laino, R.; Valdés, C. Chem. - Eur. J. 2015, 21, 16463. (c) Paraja, M .; Carmen Pérez-Aguilar, M .; Valdés, C. Chem. Commun. 2015, 51, 16241. (d) Paraja, M.; Valdés, C. Chem. Commun. 2016, 52, 6312. (e) Paraja, M .; Valdés, C. O rg. Lett. 2017, 19, 2034. (f) Barroso, R.; Paraja, M .; Cabal, M.-P.; Valdes, C. O rg. L ett. 2017, 19, 4086.

(6) (a) Plaza, M.; Valdés, C. J. A m. Chem. Soc. 2016, 138, 12061. (b) Plaza, M.; Parisotto, S.; Valdés, C. Chem. - Eur. J. 2018, 24, 14836. (c) Paraja, M.; Plaza, M .; Valdés, C. Synlett 2017, 28, 2373.

(7) Xia, Y.; Wang, J. Chem. Soc. Rev. 2017, 46, 2306.

(8) Somerecent methods for the synthesis of $\beta, \gamma$-unsaturated ketones: (a) Bao, M .; Lu, W.; C ai, Y.; Q iu, L.; Xu, X. J. O rg. Chem. 2017, 82, 13386. (b) Wu, Y.; Fu, W. C.; Chiang, C.-W.; Choy, P.Y.; K wong, F. Y.; Lei, A. Chem. Commun. 2017, 53, 952. (c) Grigalunas, M.; Ankner, T .; N orrby, P.-O .; W iest, O .; H elquist, P. J. Am. Chem. Soc. 2015, 137, 7019. (d) Ankner, T.; Cosner, C.C.; H elquist, P. Chem. Eur. J. 2013, 19, 1858. (e) Saemann, C.; Knochel, P. Synthesis 2013, 45, 1870. (f) Trofimov, B. A.; Schmidt, E. Y.; Zorina, N . V.; I vanova, E. V.; U shakov, I. A. J. Org. Chem. 2012, 77, 6880 and references cited therein.

(9) (a) Charrier, C.; Bertrand, P.; G esson, J.-P.; Roche, J. Bioorg. M ed. Chem. Lett. 2006, 16, 5339. (b) Sheridan, H.; Walsh, J. J.; Cogan, C.; Jordan, M .; M cC abe, T.; Passante, E.; Frankish, N . H. Bioor. M ed.Chem. Lett. 2009, 19, 5927. (c) Barlow, J. W.; M CH ugh, A.P.; Woods, 0 .; Walsh, J. J. Eur. J. M ed. Chem. 2011, 46, 1545. (d) H su, D.-S.; Yeh, J.-Y.; Cheng, C.-Y. O rg. Lett. 2017, 19, 5549. (d) Cheung, M .; T angirala, R. S.; Bethi, S. R.; Joshi, H . V.; Ariazi, J. L.; T irunagaru, V. G.; Kumar, S. ACS M ed. Chem. Lett. 2018, 9, 103.

(10) (a) Zou, Y.; Ding, C.; Zhou, L.; Li, Z.; Wang, Q .; Schoenebeck, F .; Goeke, A. Angew. Chem. Int. Ed. 2012, 51, 5647. (b) M artin-Fontecha, M.; Agarrabeitia, A. R.; O rtiz, M . J.; Armesto, D. O rg. Lett. 2010, 12, 4082. (c) Chang, B.; Su, Y.; H uang, D.; Wang, K.-H .; Zhang, W.; Shi, Y.; Zhang, X.; H u, Y. J. O rg. Chem. 2018, 83, 4365. (d) Demuth, M.; M ikhail, G. Synthesis 1989, 145

(11) (a) H uang, J.; Bunel, E.; Faul, M . M . Org. Lett. 2007, 9, 4343. (b) Chieffi, A.; Kamikawa, K.; Ahman, J.; Fox, J. M.; Buchwald, S. L. O rg. Lett. 2001, 3, 1897.

(12) M edina, J. M .; M oreno, J.; Racine, S.; Du, S.; Garg, N. K. Angew. Chem. Int. Ed. 2017, 56, 6567.

(13) (a) Shi, Y.; Gao, S. T etrahedron 2016, 72, 1717. (b) Cao, Z.; Zhu, H.; M eng, X.; T ian, L.; Chen, G.; Sun, X.; You, J.J. Org. Chem. 2016, 81,12401 and references cited therein.

(14) The stereochemical assignments were carried out by $2 D-N ~ M ~ R$ and selective $n 0$ e experiments ( see $S I$ for a detailed discussion).

(15) Taber, D. F.; Guo, P.J. Org. Chem. 2008, 73, 9479.

(16) (a) Barluenga, J.; T omás-Gamasa, M.; Aznar, F.; Valdés, C. N at. Chem. 2009, 1, 494. (b) Pérez-Aguilar, M. C.; Valdés, C. Angew. Chem., Int. Ed. 2012, 51, 5953. (c) Plaza, M.; Pérez-Aguilar, M. C.; Valdés, C. Chem. - Eur.J. 2016, 22, 6253.

(17) Brown, H. C.; Rangaishenvi, M. V.; Jayaraman, S. Organometallics 1992, 11, 1948. 
"This document is the Accepted Manuscript version of a Published Work that appeared in final form in O rganic L etters, copyright @ A merican C hemical Society after peer review and technical editing by the publisher. T 0 access the final edited and published work https://doi.org/10.1021/acs.orglett.8b03705 ]" 